\title{
PURE AND APPLIED, MORAL AND PRAGMATIC: THE PROPER WAY TO IMPROVE SCIENCE EDUCATION
}

\author{
Todar Lakhvich \\ International Sakharov Environmental University, \\ Republic of Belarus
}

"Non-implemented idea is not an idea yet"

Andrey Sakharov

\section{Dear Readers and Writers!}

In recent years many researchers (ROSE Project in particular) have stated the Science has become one of unpopular areas of knowledge. Most students and graduates are not going to link their fates with the Science and Technology. As the result, we are facing the decline of University Science and Technology Education, as only few talented students choose Science as their priority area of their interest and even less of them decide to teach the Science in school and University.

In view of the fact that the image of Science emerged at the intersection of interests and perceptions of the general public and scientists, it is important to understand the role of academia in shaping their own public image.

What kind of self-image do we (scientists and educators) promote?

Which kind of audience do we reach out?

How do we interact with this audience?

To explore the lessons from the history, we could find those, which are particularly obvious. Rather than contemplating the identity of Science in order to derive and support an adequate image, scientists (both researchers, policy makers and, finally, - what strange enough - educators) have preferred to hide themselves behind the industry and technology. Instead of explaining what Science is, we usually have pointed to technological progress. And when audience being questioning more critical, we propose the cliché variant of reflection with exaggerated promises of technological progress, even if nobody would listen. The tendency has become a matter of routine and widely accepted. Butt obviously the cliché approach, which is out of the interests of majority of population, leads to fiasco.

Therefore, I dare point out a specific focus on how this image can be shaped by academia to popularize Science and to make its image more attractive. Those who do Science need no longer contemplate the identity of Science. We need to find out the right spot on the interface for interaction between two parts of Science paradigm: internal (which facilitates its development including scientific researches, industry and "Pure" Education) and external (public opinion, stereotypes and cultural identities).

To some extent the public images of disciplines reflect also their intellectual state. From the one hand. it consists of the fundamental basis providing the development of the discipline body. In this Science possesses the pure character and we need to explore the theoretical basis in researches and to conduct "pure" knowledge in learning/teaching process. For this theoretical and fundamental knowledge is of great importance: we can say about "pure" Science and Education, and the Discipline aspect being the keystone 
for Science Education. On the other hand, the Science interacts with audience and thus dissolves a plenty of social problems opening new directions to industrial development and social progress. This context might be considered as the basis for applied role of Science, and doing the researches as well as shaping educational programs we taking into account the utility of Science and Science Education. The interface where two moieties intersecting gives the rise to some Philosophy paradigm, and among them Morality (what is moral or immoral in Science) and Aesthetics (what is Beautiful or Ugly). Just the reason to add these values to build the effective and attractive system of theoretically grounded, applied to needs of real life, socially oriented and finally, moral and publicly attractive Science researches and Education.

After the extensive rhetoric (just a good chance to be a little sarcastic about the author's bla-bla-bla style in scientific Journal) I wish to illustrate the "Philosophy Section" by few episodes. Although each focusing on a specific aspect, all of them span the entire history of the popularization efforts of Science and making the latter the decisive tool for contemporary society and life of common people.

The first episode is connected with a history of power consumption and the influence of the sources for energy on geopolitics. It is well known that the era of fuel materials for cars and industry and gas-oil products for power profoundly affected the development of the world's economy in the $20^{\text {th }}$ century. In this case a significant role in determining the global political processes belonged to states that took significant reserves of oil and gas. And in some cases the states with weaker economic development and primitive authoritarian systems of governance have come to define direction of the global economy and direct the geopolitical processes. Speculative groundless prices for fuel raw materials, economic blackmail and pressure have become the reality of recent years. However, world leaders had to take into account the role of those states, and as the result economically weak and autocratic Russia gained the G20 group. Just for the moment it seemed the panic have swept the Russian authorities. The main reason obviously two events in "energy" market that reveals the alternatives to expensive and exaggerated Russian gas and oil products. Both of them are connected with the development of high technologies in this field. New, unconventional energy resources are reshaping global economy and altering geopolitics.

The first is so called shale gas revolution - the elaboration and development of industrial technology for unconventional (shale) gas, which has already been known since the $19^{\text {th }}$ century. But for decades it was common place to discuss the issue as theoretical and inapplicable for industry. By contrast to conventional gas, unconventional gas (a mixture of tight gas, coal-bed methane, shale gas and hydrates) is sourced from accumulations with large spatial dimensions and indistinctly defined boundaries existing more or less independently of the water column. For unconventional gas, drilling (which is a common tool for conventional gas production) is not enough to generate a commercial flow. Some other artificial stimulus and special recovery processes are required. Two key technologies are especially relevant for shale gas. These are horizontal drilling and hydraulic fracturing, where water, sand and chemicals are injected into the horizontal borehole of the well at very high pressure to fracture the shale rocks and release the gas. Neither technology is new. Horizontal drilling emerged in the 1930s and the first well was fracked in the United States in 1947. But only few decades later the technology emerged to industrial scale and began to influence the geopolitics. Initially shale gas has become an increasingly important source of natural gas in the United States since the beginning of this century, and interest has spread to potential gas shales in the rest of the world. In 2000 shale gas provided only 1\% of U.S. natural gas production; by 2010 it was over $20 \%$ and the U.S. government's "Energy Information Administration" predicts that by 2035, 46\% of the United States' natural gas supply will come from shale gas (Stevens, 2012). And the revolution may not stay limited to the US only. The trend is catching on. Just for the moment the technologies implemented in European area. And new countries (UK, Poland and Ukraine) are emerging the energy market. Obviously the sponsored actions of some environmental organizations can not significantly influence the development of this new market. Using the NiGEM model, the study projected that over the next two decades, this additional supply could push global oil prices down, by somewhere between $\$ 33$ and $\$ 50$ (depending on a number of variables) (Wald, 2013).

The other episode is connected with the expansion of electric mobiles to car market. The first electromobiles were invented more than 100 years ago. But after the invention of effective fuel combustion technologies, as well as elaboration of sources for oil supply the petroleum engine gained a victory. The new era of vehicle electrification has begun since the 2000s when a group of companies began to develop new 
effective electromobiles. The crucial steps towards commercial production were three points: the invention of effective engine, lithium-ion battery and infrastructure. A California-based company Tesla Motors, Inc. was among the generators of this one more power supply revolution. "We can break our dependence on oil... and become the first country to have one million electric vehicles on the road by 2015," President Obama said in his January 2011 State of the Union address. Recently six states announced jointly for adoption of a range of measures including encouraging more charging stations and changing building legislation, to make it easier to own an electric car. The goal is to achieve sales of at least 3.3 million vehicles that did not have any emissions by 2025 (Wald, 2013).

The development of these technologies will have an insurmountable impact on the global economy and the world's geopolitical map, helping to prevent Russia and the Persian Gulf countries from dictating higher prices for the gas and oil they export to other (first of all European) countries. The energy world has changed. Let us beware of it!

The second episode is dedicated to the aesthetic potential of Science. In that vein, I found to be creative, funny, and thought provoking the publishing in 2003 by James Tour and Stephanie Chanteau, from the Rice University's Institute for Nanoscale Science and Technology an article in The Journal of Organic Chemistry where they used their knowledge of chemical synthesis to create the NanoPutians (Chanteau and Tour, 2003). To get a little more serious, the idea was actually part of the chemistry education program at the Rice University aimed at introducing organic chemistry and nanotechnology to young students. NanoPutians are 2-nm-tall anthropomorphic molecules in monomeric, dimeric, and polymeric form. Put simply, they are people shaped molecules synthesized using a string of chemical reactions. Tour and Chanteau went as far as creating the life cycle of the NanoPutian from NanoKid to NanoProfessional. Let's meet the family:

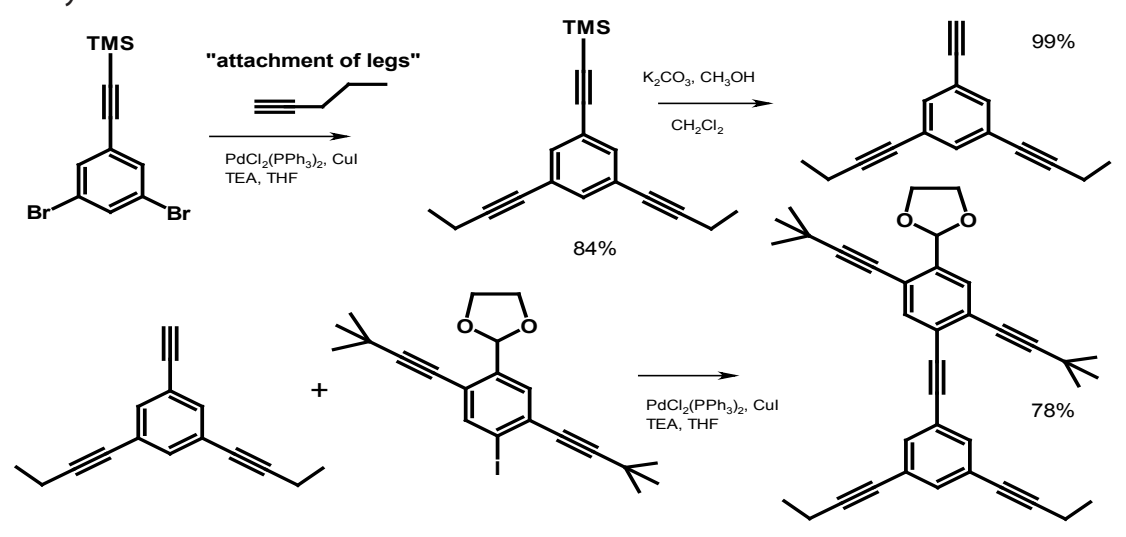

The article was done on the basis of synthetic research in good scientific traditions, but obviously possessed a great aesthetic and educational potential. The most interesting fact is that it was found nanokids - when taken on specific surface - gave the nanomaterials. That gave rise to commercial usage of the invention. Just concept of Beautility reveals a great utility (pragmatic) potential of beautiful things (aesthetic, which can be regarded as moral component, background) [(Lakhvich, 2010)

And finally, I dare mention a moral aspect of Science researches and Education. One can say about the immorality of Science (just regarded O. Wild in his "Portrait of Dorian Gray", that "there is not such thing as moral or immoral books. Books are well written or badly written, That is all"). But I do strengthen the idea the both Science and Education should be Moral. And the personality of Nobel winner great Physicist and fighter for human rights professor Andrey Sakharov confirms the idea. When looking through Sakharov's biography and analyzing his deeds one can come to a conclusion he remained in various fields and in various periods as a man of exact sciences, a construction engineer, a physicist, demiurge and inventor. We can find the confirmation in his work in designing thermonuclear devices both super-weapon, but "not for war but for the balance of power throughout the world" and energetics (applied Science), his theoretical researches in the field of particle physics and cosmology (pure Science), his defending human rights and struggle for peaceful usage of Science inventions (Moral context) and finally he struggled for new political system and independence of nations in the former Soviet empire (very pragmatic as it 
leaded to contemporary, liberal and thus, more effective society). "The visible result may be the figures at the end of a formula-saturated paper or release of a victim of political repressions - no matter: in any case it was a sort of scientific research, and special holism of Sakharov's mentality proposed the essentially unexpected steps to the solution, which were at first often misunderstood or sometimes even shocking for his contemporaries" (Altshuler, 2009). Just according to Sakharov's motto: "Non-implemented idea is not an idea yet".

\section{References}

Altshuler, B. (2009). Andrei Sakharov as a physicist in all facets of his life. Report at the Sakharov Memorial Session of the 4th International Sakharov Conference on Physics, May 18-23, 2009, Moscow. Online proceedings http://www.sc4.Ipi.ru/proc.html

Chanteau, S., Tour, J. (2003). Synthesis of Anthropomorphic Molecules. Journal of Organic Chemistry, 68, 87508766.

Husain, S. R. (2013). Shale Gas Revolution Changes Geopolitics. Saudi Gazette, Nov. 03.

Lakhvich, T. (2010). Science Education: Search for Harmony and Beauty. Journal of Baltic Science Education, 9 (2), 84-86.

Stevens, P. (2012). The 'Shale Gas Revolution': Developments and Changes. Energy, Environment and Resources, $2,12$.

Wald, M. (2013). 8 States Teaming Up to Support Electric Cars. New York Times, Oct. 24.

Received: October 05, 2013

Accepted: October 25, 2013

Todar Lakhvich PhD., Associate Professor, International Sakharov Environmental University, Minsk, Republic of Belarus.

E-mail: tolakh@bspu.unibel.by 